\title{
Nutritional breakfast quality and cardiometabolic risk factors: Health Survey of São Paulo, a population-based study
}

\author{
Paula Victória Félix ${ }^{1}$, Jaqueline Lopes Pereira ${ }^{\top} \odot$, Ana Carolina Barco Leme ${ }^{1,2}{ }^{\circ}$, \\ Michelle Alessandra de Castro ${ }^{1}$ and Regina Mara Fisberg ${ }^{1, *}$ \\ 'Department of Nutrition, School of Public Health, University of São Paulo, Av. Dr. Arnaldo, 715, São Paulo, SP, \\ CEP - 01246-904, Brazil: 'Family Relations and Applied Nutrition, University of Guelph, Guelph, Canada
}

Submitted 3 March 2020: Final revision received 30 May 2020: Accepted 8 July 2020: First published online 25 August 2020

\begin{abstract}
Objective: To evaluate the association between nutritional quality of breakfast and cardiometabolic risk factors.

Design: Cross-sectional study, 2015 Health Survey of São Paulo (2015 ISA-Capital) with Focus on Nutrition Study (2015 ISA-Nutrition).

Settings: Population-based study, with a representative sample of adults and elderlies living in São Paulo, Brazil.

Participants: The sample included 606 adults (aged 20-59 years) and 537 elderlies (aged $\geq 60$ years) from the 2015 Health Survey of São Paulo. Dietary intake was assessed by at least one 24-h recall. Breakfast quality was evaluated using the proposed Brazilian Breakfast Quality Index (BQI), ranging scores from 0 to 10. BQI associations with sociodemographic, lifestyle, dietetic and cardiometabolic variables were estimated using survey-weighted multiple logistic regression models.

Results: Being $\geq 60$ years of age, self-identifying as White or Asian, having a per capita family income with $\geq 1$ minimum wage, being sufficiently active at leisure time and non-smoker were associated with better scores of BQI. A higher BQI score was inversely associated with elevated blood pressure (OR 0.81, $95 \% \mathrm{CI}$ $0.70,0.94$ ), fasting glucose (OR 0.85, $95 \%$ CI 0.73, 0.98), HOMA-IR (OR 0.86, $95 \%$ CI 0.74, 0.98), total cholesterol (OR 0.87, $95 \%$ CI 0.76, 0.99), LDL-C (OR $0.85,95 \%$ CI $0.74,0.97$ ), metabolic syndrome (OR 0.82, $95 \%$ CI 0.72, 0.93) and being overweight (OR 0.87, $95 \%$ CI 0.76, 0.99).

Conclusions: Breakfast quality of Brazilian adults needs improvement with disparities across some sociodemographic factors. BQI was associated with lower odds of cardiometabolic risk factors, suggesting a beneficial effect in this population and emphasising the role of breakfast in reducing the risk of CVD.
\end{abstract}

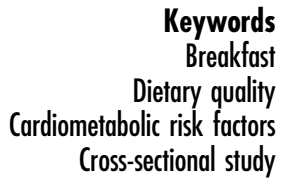

CVD are the leading causes of death and burden disease, taking an estimated 17.9 million lives each year worldwide. Obesity, hypertension, type 2 diabetes (T2D), dyslipidaemia and smoking have been identified as important risk factors for CVD, and a higher burden of risk factors is associated with a raising lifetime risk for $\mathrm{CVD}^{(1)}$. Eastern European countries have the highest prevalence of CVD, ranging from 55 to $60 \%$, followed by Australia, Canada and the United States with rates around $30 \%$. A similar trend has been described in Brazil, particularly among females $(28 \cdot 5-29 \cdot 1 \%)^{(2)}$.

Evidence has shown that good adherence to dietary guideline recommendations has been associated with reduced weight, cardiovascular and other metabolic disorder risk factors ${ }^{(3-5)}$, and has demonstrated long-term sustainability and nutritional quality ${ }^{(3)}$. Dietary intake is closely connected with eating behaviours and habits. For example, breakfast, which is often recognised as the 'most important meal of the day', is associated many health benefits $^{(6-11)}$. Studies from Spain ${ }^{(12)}$, the USA ${ }^{(9)}$ and the $\mathrm{UK}^{(13)}$ have evaluated the contribution of breakfast to daily macro- and micronutrients intake, reporting that regular breakfast consumers have significantly higher intake of fibre, vitamins and minerals ${ }^{(13,14)}$ and consume less energy-dense food sources during the day ${ }^{(13)}$. Although guidelines from different countries ${ }^{(15-19)}$ emphasised the 
importance of breakfast, the optimal nutrient composition is not well established, and population's eating behaviours are different in terms of their social, cultural and economic aspects $^{(20,21)}$. For example, the breakfast most frequently consumed in Brazil consists of milk and dairy products, coffee and tea and grain-based, especially bread, which may differ from that of other populations ${ }^{(21)}$.

Given the importance of evaluating breakfast's nutritional quality, assessment methods have been developed, mainly in high-income countries ${ }^{(20,22-30)}$. Some of them consider the total energy and nutrients intake, with items recognised as critical components in order to maximise the benefits of this meal. Moreover, food sources and amount consumed are taken into account ${ }^{(25,28)}$. In Brazil, the Breakfast Quality Index (BQI) was proposed using a national dataset with 22279 breakfast consumers having a mean age of $53 \pm 0.2$ years and $53 \%$ being female. Findings showed that $71 \%$ of participants fell into medium BQI category and $6 \%$ into a high category. Consumers with high BQI had a higher intake of fruit and vegetables and higher daily intake of energy, carbohydrates, fibre, total sugar, sodium, potassium, phosphorus, thiamine, riboflavin, niacin, folate and vitamins B6, A, C and D, and lower trans fatty acids, compared with those from low and medium BQI categories. Thus, promoting a high-quality breakfast may contribute to a better nutrient intake and achievement of daily requirements ${ }^{(21)}$.

Whereas there are studies supporting breakfast consumption as a protective factor against obesity and associated comorbidities, such as TD2 and high blood pressure $(\mathrm{BP})^{(8,31)}$, there is a gap in studies conducted in low- and middle-income, including Brazil, investigating breakfast quality and risk factors for cardiometabolic diseases in non-institutionalised and older adults ${ }^{(8)}$. Therefore, the purpose of the present study was to examine the associations between (1) breakfast quality and cardiometabolic risk factors; (2) breakfast quality, socioeconomics, lifestyle aspects, weight status and energy and nutrients of public health concern for adults and older adults in the city of São Paulo.

\section{Methods}

\section{Study sample}

The 'Health Survey of São Paulo' (Portuguese acronym ISACapital) is a household population-based, cross-sectional study conducted every 5 years. Three waves were carried out in 2003, 2008 and 2015. Data were gathered from the 2015 survey with a probabilistic sample of individuals $>12$ years of age living in urban areas of São Paulo. The present study was designed to collect information on aspects relating to diet and other lifestyle aspects, acute and chronic morbidities, preventive practices and use of health services. All these were obtained through stratified sampling by clusters carried out in two stages: census tracts

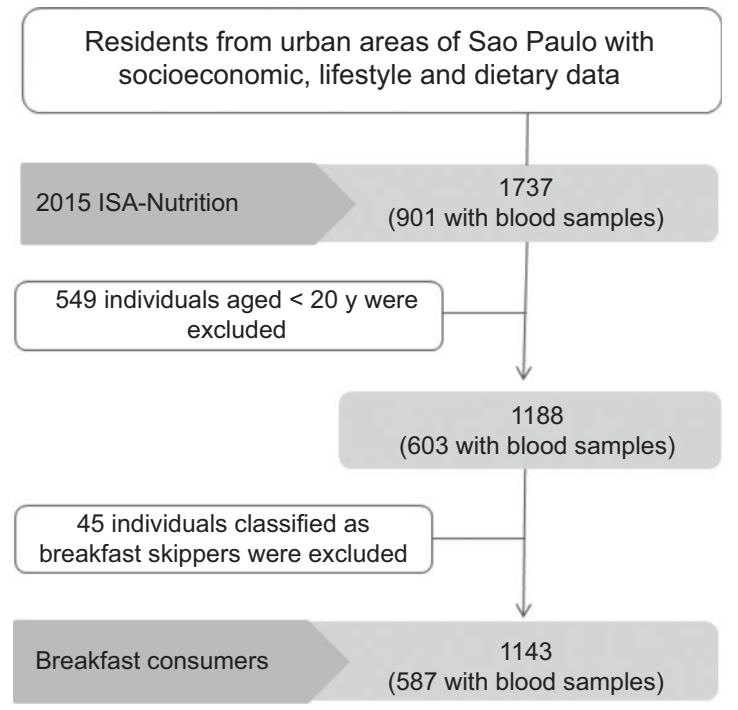

Fig. 1 Description of the sample in the 2015 Health Survey of São Paulo with Focus on Nutrition Study (2015 ISA-Nutrition) eligible for the present study

and households. More details of the present study and sample design have been published elsewhere ${ }^{(32)}$.

For the present study, a subsample of the 2015 ISACapital was used. This subsample was drawn to compose the 'Health Survey of São Paulo with Focus on Nutrition', named ISA-Nutrition. Dietary data from 1737 individuals were collected. We considered only adults (aged 20-59 years) and older adults ( $\geq 60$ years), classified as breakfast consumers (individuals who reported this meal in at least one recall). Thus, our final sample composed of 1143 individuals with complete dietary data, and 587 with blood samples to identify their cardiometabolic risk factors. Participant's eligibility for the present study can be found in Fig. 1.

\section{Data collection and processing}

Trained interviewers collected data on sociodemographics and lifestyle behaviours through a structured questionnaire. For the present study, the following variables were used: age (categorised a 20-59 years or $\geq 60$ years), sex (male or female), self-identified race (White or Asian, and Black, mixed race or Native), per capita family income $(\leq 1$ or $>1$ minimum wage, calculated by the sum of total income of all family members divided by the number of family members living in the house), household level of education (below elementary school or above high school) and smoking status (smoker or non-smoker).

Physical activity (PA) data were obtained through the validated International Physical Activity Questionnaire (IPAQ) long version ${ }^{(33)}$. Leisure time PA was taken into account for the present study (e.g. walking, dancing, gardening, hiking and swimming), and participants were classified as meeting or not meeting the recommendations 
for PA (i.e. $\geq 150 v$. $<150 \mathrm{~min} /$ week) according to WHO guidelines $^{(34)}$.

Participants' self-reported body weight and height were used to calculated BMI using the standard formula: weight $(\mathrm{kg}) /[\text { height }(\mathrm{m})]^{2}$. BMI was transformed into a categorical variable reflecting the cut-off values for body weight status for adults ${ }^{(35)}$ and older adults ${ }^{(36)}$. Thus, two categories were used: non-overweight (BMI $<25 \mathrm{~kg} / \mathrm{m}^{2}$ for adults and $<28 \mathrm{~kg} / \mathrm{m}^{2}$ for older adults) and overweight/obese (BMI $\geq 25 \mathrm{~kg} / \mathrm{m}^{2}$ for adults and $\geq 28 \mathrm{~kg} / \mathrm{m}^{2}$ for older adults). Previously, self-reported measure was validated in this population, observing high sensitivity and specificity for that matter ${ }^{(37)}$.

\section{Dietary intake}

Dietary data were collected from at least one 24-h recall (24hR) on non-consecutive days, representing different week days and weekend days and seasons of the year. The first $24 \mathrm{hR}$ was collected during home visits, and the second via a telephone interview using the automated multiple pass method ${ }^{(38)}$, that is, a standardised procedure with prompts and probes to capture the most reliable information on dietary intake. The Nutrition Data System for Research (NDS-R) software (version 2014; Nutrition Coordinating Center, University of Minnesota) was used to calculate energy and nutrients from dietary recalls. As NDS-R uses the US Department of Agriculture's food composition database, energy and nutrient values provided in the present study were compared with other Brazilian food composition databases ${ }^{(39,40)}$. Thus, dietary outcomes were then compared and discrepancies corrected before data processing.

The overall diet quality and their components were evaluated based on the Brazilian Healthy Eating IndexRevised (BHEI-R) ${ }^{(41)}$, which has conformity to the 2006 Dietary Guidelines for the Brazilian Population ${ }^{(42)}$, the $\mathrm{WHO}^{(43)}$, the Institute of Medicine ${ }^{(44)}$, the Healthy Eating Index 2005 for Americans ${ }^{(45)}$ and the Brazilian Society of Cardiology ${ }^{(46)}$. This measurement assesses adequacy to a moderation perspective. BHEI-R has twelve components including nine adequacy components, that is, total fruits; whole fruits; total vegetables; dark green and orange vegetables and legumes; total grains; whole grains; milk and dairy; meat, eggs and legumes; oils (ratio of MUFA and PUFA to SFA, and three moderation components: saturated fat, sodium and SoFAAS (solid fats, alcohol and added sugars). BHEI-R is examined as intake per $1000 \mathrm{kcal}$ and scored 5-20 points with the total BHEI score as the sum of all components. BHEI-R's total score ranges from 0 to 100, with higher scores indicating better diet quality ${ }^{(41)}$. Therefore, the impact on breakfast quality is differentiated when considering BHEI-R's overall diet quality.

Food and beverages that most contributed to breakfast's total energy intake were identified. This resulted in 280 different items reported by the first $24 \mathrm{hR}$, which were grouped based on nutritional value, eating frequency and other diet habits of individuals living in the city of São Paulo. Food and beverages consumed by under $2 \%$ of the study sample were not grouped because of the high variability in terms of nutrient values and low frequency of intake. Descriptions of breakfast food groups and prevalence of consumers according to age group and BQI categories are described in online supplementary material, Supplement Table 1. Energy contribution of each group was determined based on the method proposed by Block et al. ${ }^{(47)}$. Breakfast energy contribution (percentage) of food groups from ISA-Nutrition based on age groups and BQI categories is available in online supplementary material, Fig. S1.

\section{Breakfast definition}

Breakfast was defined as the type of meal that was selfreported by participants. Only seven participants did not report the type of meal in the present study. The definition of breakfast was consistent with that previously published in literature ${ }^{(6)}$. Thus, it is the first meal of the day that breaks the fast after the longest period of sleep and is consumed within a couple of hours (i.e. generally 2-3 hours) of waking up, and it comprises food and beverages from at least one food group and may be consumed at any location.

Individuals who provided two dietary recalls were classified as breakfast consumers if reported at both $24 \mathrm{hR}$, occasional consumers if reported in the first or second recall, or breakfast skippers if not reported at both recalls. Individuals who had only one dietary recall were classified as breakfast consumers or skippers according to their reports.

\section{Brazilian Breakfast Quality Index}

Breakfast quality was evaluated based on BQI, which was proposed by Pereira et al. $(2017)^{(21)}$. BQI has ten components combining food groups, energy and nutrients of public health concern ${ }^{(48)}$. It includes three food group components - cereals and other grain products, fruit or vegetables and dairy products; six energy and nutrient components - breakfast energy, free sugar, saturated fat, total fibre, calcium and sodium; and one component considering altogether the three food groups in at least one of the days of dietary assessment. Each BQI component is examined as an intake of $15-25 \% \mathrm{kcal}$ per day and scored $0-1$ point with the total BQI score as the sum of all components. The index ranges from 0 to 10 , with higher scores indicating better breakfast quality ${ }^{(21)}$.

Qualitative criteria were used to group the foods based on component scores. Each component received 0 for not consuming, or 1 for consuming, in at least one $24 \mathrm{hR}$, not considering the amount reported. Mixed preparations were aggregated into multiple groups; for example, oatmeal was added to the groups 'cereals and other grain 
products' and 'dairy products' due to having oat and milk as main ingredients.

Energy and nutrient components were scored using a quantitative criterion. Individuals would receive a score of 1 if reached the following recommendations: (a) breakfast representing $15-25 \%$ of total energy intake; (b) free sugar $<10 \%$ of total energy intake/number of eating occasions of the individual; (c) saturated fat intake $<10 \%$ of total energy intake/number of eating occasions of the individual; (d) total fibre intake $>25 \mathrm{~g} /$ number of eating occasions of the individual; (e) calcium intake $\geq 20 \%$ of RDA according to age group; (f) sodium intake $<2000 \mathrm{mg} /$ number of eating occasions of the individual ${ }^{(21)}$.

Since the recommendations are based on daily intakes of nutrients and no recommendation for breakfast nutrient intakes exists, the average of intake was considered if participants reported both $24 \mathrm{hR}$. Individuals who consumed only non-caloric beverages (e.g. coffee, tea and diet soda) on both days scored 0 in BQI, as well as those who only consumed calories from regular sodas or alcoholic beverages.

\section{Cardiometabolic risk factors}

A standard protocol with specific instructions for conducting all assessments was used by a trained nursing assistant to ensure consistency. Blood samples were collected using venepuncture after $12 \mathrm{~h}$ of overnight fasting, $72 \mathrm{~h}$ of no alcohol intake and no intense PA prior to data collection. The present study had the following cardiometabolic risk factors as outcomes: (i) waist circumference collected in triplicate ${ }^{(49)}$; (ii) BP was measured using an automatic device (Omron; model HEM-712C); (iii) glucose was analysed by colorimetric enzymatic assay (Cobas; Roche Diagnostics $\mathrm{GmbH}$ ); (iv) insulin was analysed by multiplex immunoassay (LINCOplex ${ }^{\circledR}$; Linco Research Inc.); and (v) lipid profile was determined by enzymatic-colorimetric method (Roche Diagnostics GmbH). More details are described elsewhere $^{(32)}$.

The definitions of cardiometabolic risk factors were met in accordance to the guidelines available at the time of conduct of the present study. The cut-off criteria for each cardiometabolic risk factor were as follows: waist circumference $\geq 80 \mathrm{~cm}$ for women and $\geq 94 \mathrm{~cm}$ for men ${ }^{(50)}$, fasting glucose level $\geq 126 \mathrm{mg} / \mathrm{dL}$ or reported taking anti-diabetic drugs $^{(51)}$, total cholesterol (TC) $\geq 240 \mathrm{mg} / \mathrm{d}$, LDL cholesterol (LDL-C) $\geq 160 \mathrm{mg} / \mathrm{dL}, \mathrm{TG} \geq 200 \mathrm{mg} / \mathrm{dL}$ and HDL cholesterol (HDL-C) $<40 \mathrm{mg} / \mathrm{dL}^{(52)}$. Individuals who reported using drugs to lower their lipid profile were identified as having dyslipidaemia ${ }^{(50)}$. High BP was defined as having a systolic $\mathrm{BP} \geq 140 \mathrm{mmHg}$ and/or diastolic $\mathrm{BP} \geq 90 \mathrm{mmHg}$ or use of anti-hypertensive drugs ${ }^{(53)}$.

The homeostasis model assessment of insulin resistance (HOMA-IR) was calculated using the formula: [fasting blood glucose $(\mathrm{mg} / \mathrm{dL}) \times$ fasting insulin $(\mu \mathrm{U} / \mathrm{mL})] / 405$, and the cut-off value for the Brazilian population was
$2 \cdot 71^{(54)}$. Metabolic syndrome (MetS) classification followed the criteria recommended by the American Heart Association $^{(50)}$. The presence of any three of the following five risk factors constitutes a diagnosis of MetS: high BP or use of anti-hypertensive drugs; high waist circumference; high fasting glucose or use of anti-diabetic drugs; high TG, low HDL or use of drugs to lower the lipid profile.

\section{Statistical analysis}

Descriptive analyses were conducted based on the categories of BQI scores as indicated: low ( $0-3$ points), medium (4-6 points) and high (7-10 points). Data were presented considering non-parametric distribution. Differences between groups were tested by Theil-Sen median test for complex survey, and the post hoc Dunn test was used to identify significance between groups. Categorical variables were evaluated using Pearson's $\chi^{2}$ test. Statistical modelling techniques incorporated in the Multiple Source Method software ${ }^{(55)}$ were used to provide usual dietary intakes after adjusting for intrapersonal variance in energy and nutrient intake at breakfast and total daily energy intake.

Stepwise logistic regression models, after controlling for confounding factors (i.e. age, BMI, race, income status, household education level, smoking status, PA level and total BHEI-R score $)^{(41)}$, were conducted to verify associations between breakfast quality and cardiometabolic risk factors. BMI was not adjusted for the models that had participant being overweight and with an increased waist circumference as an outcome. Results were presented as OR and $95 \%$ CI. Hosmer-Lemeshow goodness-of-fit test was used for the calibration of each model. All analyses were conducted in STATA 14.0 software with sample weights considering the complex survey design with significance level set at $P<0.05$.

\section{Results}

In our sample of adults, $5.8 \%$ were breakfast skippers, $2.4 \%$ occasional consumers and $91.8 \%$ breakfast consumers. For older adults, the frequency was 1.1, 2.5 and 96.4\% for breakfast skippers, occasional and consumers, respectively. About $86 \%(95 \%$ CI 83.2, 88.3) of breakfast and occasional consumers had the meal between 06.00 and 10.00 hours.

Table 1 contains the descriptive analysis of participants according to BQI categories. The sample predominantly composed of adults having $>9$ years of schooling, per capita family income $>1$ minimum wage, never being a smoker and not meeting the guidelines for PA. Similar proportions were found for sex, self-declared race and body weight. The majority of the population was in the middle BQI category (67\%), and the average score was 4.9 (95\% CI 4.8, 5.1). Fifteen individuals (1.3\%) scored 0 
Table 1 Socioeconomic and lifestyle characteristics of the adult and older adult population in ISA-Nutrition (2015) according to Brazilian Breakfast Quality Index (BQI) categories*

\begin{tabular}{|c|c|c|c|c|c|c|c|c|c|c|c|c|c|c|c|}
\hline \multirow[b]{3}{*}{ Variables } & \multirow[b]{3}{*}{$n$} & & & \multicolumn{6}{|c|}{ Categories of BQI } & \multirow[b]{3}{*}{$P \ddagger$} & \multirow[b]{3}{*}{ Mean score } & \multirow[b]{3}{*}{ SD } & \multirow[b]{3}{*}{ Median } & \multirow[b]{3}{*}{ IQR } & \multirow[b]{3}{*}{$P \S$} \\
\hline & & \multicolumn{2}{|c|}{$\begin{array}{l}\text { Total population } \\
(n 1143)\end{array}$} & \multicolumn{2}{|c|}{$\begin{array}{c}\text { Low }(0-3) \\
\text { scores }(n 183) \\
17 \%\end{array}$} & \multicolumn{2}{|c|}{$\begin{array}{c}\text { Medium (4-6) } \\
\text { scores }(n 772) \\
67 \%\end{array}$} & \multicolumn{2}{|c|}{$\begin{array}{c}\text { High }(7-10) \\
\text { scores }(n 188) \\
16 \%\end{array}$} & & & & & & \\
\hline & & $\%$ & $95 \% \mathrm{Cl}$ & $\%$ & $95 \% \mathrm{Cl}$ & $\%$ & $95 \% \mathrm{Cl}$ & $\%$ & $95 \% \mathrm{Cl}$ & & & & & & \\
\hline \multicolumn{16}{|l|}{ Age group } \\
\hline Adults (20-59 years) & 606 & 69.5 & $65 \cdot 8,72 \cdot 9$ & $18 \cdot 9$ & $15 \cdot 7,22 \cdot 7$ & $68 \cdot 9$ & $64 \cdot 9,72 \cdot 6$ & $12 \cdot 1$ & $9 \cdot 4,15 \cdot 5$ & & $4 \cdot 7$ & $4.6,4.9$ & 5 & 4,6 & \\
\hline Older adults ( $>60$ years) & 537 & $30 \cdot 6$ & $27 \cdot 1,34 \cdot 2$ & $11 \cdot 0$ & $8 \cdot 2,14 \cdot 7$ & $62 \cdot 8$ & $56 \cdot 9,68 \cdot 4$ & $26 \cdot 1$ & $21 \cdot 4,31.5$ & $<0.001$ & 5.4 & $5 \cdot 2,5 \cdot 6$ & 5 & 4,7 & $<0.001$ \\
\hline \multicolumn{16}{|l|}{ Sex } \\
\hline Female & 608 & $50 \cdot 0$ & $46 \cdot 4,53 \cdot 6$ & $14 \cdot 5$ & $11 \cdot 3,18 \cdot 6$ & $69 \cdot 0$ & $63 \cdot 6,73 \cdot 5$ & $16 \cdot 6$ & $13 \cdot 1,20 \cdot 9$ & & $5 \cdot 0$ & $4 \cdot 8,5 \cdot 1$ & 5 & 4,6 & \\
\hline Male & 535 & $50 \cdot 0$ & $46 \cdot 4,53 \cdot 6$ & 18.5 & $14 \cdot 9,22 \cdot 6$ & 65.4 & $60 \cdot 6,69 \cdot 8$ & $16 \cdot 2$ & $12 \cdot 6,20 \cdot 5$ & 0.316 & 4.9 & $4 \cdot 7,5 \cdot 1$ & 5 & 4,6 & 0.730 \\
\hline \multicolumn{16}{|l|}{ Self-declared race } \\
\hline White, Asian & 609 & 52,2 & $49 \cdot 0,57 \cdot 4$ & $13 \cdot 1$ & $10 \cdot 0,17 \cdot 0$ & $66 \cdot 6$ & $61 \cdot 0,71 \cdot 8$ & $20 \cdot 2$ & $16 \cdot 1,25 \cdot 2$ & & $5 \cdot 1$ & $4 \cdot 9,5 \cdot 3$ & 5 & 4,6 & \\
\hline Black, mixed race, Native & 526 & $47 \cdot 7$ & $42 \cdot 6,50 \cdot 9$ & $20 \cdot 4$ & $17 \cdot 0,24 \cdot 3$ & 67.4 & $63 \cdot 2,71 \cdot 2$ & $12 \cdot 2$ & $9 \cdot 3,15 \cdot 9$ & $<0.001$ & 4.7 & $4.5,4.9$ & 5 & 4,7 & 0.001 \\
\hline \multicolumn{16}{|l|}{ Education of households } \\
\hline Below elementary school & 585 & $45 \cdot 9$ & $41 \cdot 3,50 \cdot 5$ & $18 \cdot 6$ & $15 \cdot 1,22 \cdot 7$ & $69 \cdot 2$ & $64 \cdot 9,73 \cdot 1$ & $12 \cdot 2$ & $9 \cdot 5,15 \cdot 6$ & & 4.8 & $4 \cdot 6,5 \cdot 0$ & 5 & 4,6 & \\
\hline Above high school & 524 & $54 \cdot 1$ & $49 \cdot 5,58 \cdot 7$ & 14.9 & $11 \cdot 0,19 \cdot 9$ & 64.7 & $58 \cdot 8,70 \cdot 1$ & $20 \cdot 4$ & $16 \cdot 4,25 \cdot 1$ & 0.010 & $5 \cdot 1$ & $4 \cdot 9,5 \cdot 3$ & 5 & 4,6 & 0.018 \\
\hline \multicolumn{16}{|l|}{ Per capita family income } \\
\hline$\leq 1 \mathrm{MW} \dagger$ & 483 & $44 \cdot 2$ & $39 \cdot 0,49 \cdot 5$ & $22 \cdot 2$ & $18 \cdot 7,26 \cdot 3$ & $68 \cdot 8$ & $64 \cdot 3,73 \cdot 0$ & 8.9 & $6 \cdot 5,12 \cdot 1$ & & 4.6 & $4 \cdot 4,4.7$ & 5 & 4,5 & \\
\hline$>1 \mathrm{MW} \dagger$ & 559 & $55 \cdot 8$ & $50 \cdot 5,60.9$ & 11.4 & $8 \cdot 2,15 \cdot 6$ & $66 \cdot 3$ & $61 \cdot 3,71 \cdot 0$ & $22 \cdot 3$ & $18 \cdot 1,27 \cdot 0$ & $<0.001$ & $5 \cdot 2$ & $5 \cdot 0,5 \cdot 4$ & 5 & 4,6 & $<0.001$ \\
\hline \multicolumn{16}{|l|}{ Leisure time physical activity } \\
\hline Meet the recommendation & 192 & $17 \cdot 8$ & $15 \cdot 2,20 \cdot 6$ & $16 \cdot 4$ & $10 \cdot 8,24 \cdot 2$ & $60 \cdot 4$ & $51 \cdot 6,68 \cdot 5$ & 23.2 & $16 \cdot 4,31 \cdot 6$ & & $5 \cdot 3$ & $4 \cdot 9,5 \cdot 6$ & 5 & 4,6 & \\
\hline Don't meet the recommendation & 951 & $82 \cdot 2$ & $79.4,84.8$ & $16 \cdot 5$ & $13 \cdot 8,19 \cdot 6$ & 68.5 & $65 \cdot 0,71.9$ & $15 \cdot 0$ & $12 \cdot 3,18 \cdot 1$ & 0.049 & $4 \cdot 8$ & $4 \cdot 7,5 \cdot 0$ & 5 & 4,6 & 0.058 \\
\hline \multicolumn{16}{|l|}{ Smoking status } \\
\hline Non-smoker & 959 & 83.8 & $81 \cdot 3,86 \cdot 1$ & 14.5 & $11 \cdot 7,17 \cdot 9$ & $67 \cdot 6$ & $63 \cdot 4,71.6$ & $17 \cdot 8$ & $14 \cdot 8,21 \cdot 4$ & & $5 \cdot 0$ & $4 \cdot 9,5 \cdot 2$ & 5 & 4,6 & \\
\hline Smoker & 181 & $16 \cdot 2$ & $13 \cdot 9,18 \cdot 6$ & $26 \cdot 3$ & $19 \cdot 7,34 \cdot 3$ & $64 \cdot 4$ & $56 \cdot 3,71.9$ & $9 \cdot 2$ & $5 \cdot 8,14.5$ & $<0.001$ & 4.4 & $4 \cdot 2,4 \cdot 7$ & 4 & 3,5 & 0.003 \\
\hline \multicolumn{16}{|l|}{ Body weight } \\
\hline Without being overweight & 597 & 51.5 & $47 \cdot 8,55 \cdot 2$ & $16 \cdot 8$ & $12 \cdot 6,22 \cdot 0$ & 64.4 & $58 \cdot 8,69 \cdot 6$ & $18 \cdot 8$ & $15 \cdot 2,23 \cdot 1$ & & $5 \cdot 0$ & $4 \cdot 9,5 \cdot 2$ & 5 & 4,6 & \\
\hline Overweight & 521 & 48.5 & $44 \cdot 8,52 \cdot 2$ & $16 \cdot 2$ & $12 \cdot 9,19 \cdot 2$ & 69.9 & $65 \cdot 2,74 \cdot 2$ & 13.9 & $10 \cdot 9,17 \cdot 4$ & 0.156 & $4 \cdot 8$ & $4 \cdot 7,5 \cdot 0$ & 5 & 4,6 & 0.257 \\
\hline
\end{tabular}

MW, minimum wage.

${ }^{*}$ All the analyses took into account the sampling survey design.

†Values were adjusted by the number of individuals in the household. One MW was approximately US\$ 236 in 2015.

$\ddagger$ Differences across BQI categories were evaluated using Pearson's $\chi^{2}$ test.

$\S$ Theil-Sen test was applied for comparing medians across socioeconomic and lifestyle variables. 
in BQI. Individuals with higher family education background, family per capita income and White or Asian self-declared race showed better BQI scores. Older adults had a better BQI score $(5 \cdot 4,95 \%$ CI 5.2, 5.6), and smokers had the worst score $(4 \cdot 4,95 \%$ CI $4 \cdot 1,4 \cdot 6)$.

Food groups most consumed ( $>30 \%$ of adults and older adults) were 'coffee' (74.1\%), 'white bread and crackers' (71.2 \%), 'milk' (56.4\%), 'sugar, honey and jams' (53.7\%) and 'butter and margarine' (43.4\%). 'Milk' and 'butter and margarine' were not the most consumed food groups for participants in the lower BQI category. Those placed in the high BQI category had a lower intake of 'butter and margarine' and 'sugar, honey and jam', and other two groups were added to this category: 'fruits' and 'dairy products' (see online supplementary material, Table S1).

The thirteen food groups that accounted for up to $90 \%$ of breakfast energy intake are described in online supplementary material, Fig. S1. The five energy breakfast sources of adults and older adults were 'white bread and crackers', 'butter and margarine', 'milk', 'sugar, honey, and jams' and 'dairy products'. When considering participants classified in the low BQI category, 'sugar, honey and jams' and 'sweet and candies' contributed the most to breakfast energy intake compared with 'milk'. Participants in the medium BQI category had a more significant intake of 'milk' and 'dairy products', and those in the high BQI category had 'white breads and crackers', 'milk', 'fruits', 'dairy products' and 'butter and margarine' as major sources.

Participants in the higher BQI category had an increased intake at breakfast of proteins, total fibres and calcium, but a decrease in the intake of added sugars, carbohydrates and sodium. When considering the total diet, there was an increase in SFA, total fibres, calcium and overall BHEI-R, and a decrease in added sugars, carbohydrates and sodium in those located in the better BQI category. All significant differences were shown at $P<0.001$ (Table 2).

Table 3 evaluates the associations between BQI score and cardiometabolic risk factors. Better BQI score was associated with lower levels of BP (OR 0.81, $95 \%$ CI $0.70,0.94)$, fasting glucose (OR 0.85, $95 \%$ CI 0.73, 0.98), HOMA-IR (OR 0.86, 95 \% CI 0.74, 0.98), TC (OR 0.87, $95 \%$ CI 0.76, 0.99), LDL-C (OR 0.85, $95 \%$ CI 0.74, 0.97), MetS (OR 0.82, $95 \%$ CI 0.72, 0.93) and being overweight (OR $0.87,95 \%$ CI $0.76,0.99$ ) after adjusting for covariates. There were no significant associations between the three categories of BQI (i.e. low, medium and high) and all the cardiometabolic risk factors.

\section{Discussion}

The present study examined the association between breakfast quality and cardiometabolic risk factors from a representative sample of adults and older adults living in the city São Paulo, Brazil. Results indicated that breakfast quality was inversely associated with $\mathrm{BP}$, fasting glucose,
HOMA-IR, TC, LDL-C, MetS and overweight. Older adults were more likely to have a better overall BQI score than adults, as well as those who self-declared as being White, being more educated, earning $>1$ minimum wage per month and had never smoked. Given that sociodemographics have an important role on individuals' diets, shaping diet quality ${ }^{(56)}$, mainly the breakfast, will have an impact on the development of lifelong healthy habits and would decrease the prevalence of obesity and other cardiometabolic disorders ${ }^{(57)}$.

The present study showed that only $4.4 \%$ of adults and older adults are skipping breakfast, with a slightly lower prevalence than what was found by the Brazilian Household Budged Survey, 2008-9 (13.3 \%)(21). Similar findings were found for adults living in high-income countries, such as the US $(5 \cdot 1 \%)^{(58)}$, France $(4 \%)^{(59)}$ and Spain $(5 \%)^{(60)}$, but older adults from France and Spain showed that only up to $1 \%$ of them were skipping breakfast ${ }^{(59,60)}$. Sociocultural diversity can explain the differences found between individuals living in a large and business city and the whole country. Sociocultural aspects are considered an important determinant of eating behaviours ${ }^{(56)}$. Moreover, the definition and frequency of consumption of breakfast have been less consistent, implying that breakfast meals are homogeneous ${ }^{(6)}$.

In the current study, an examination of different categories of breakfast quality showed that those in the highest category of BQI had a better nutrient profile, corroborating with previous studies ${ }^{(9,12,13)}$. This also included higher intakes of dairy products, whole-wheat/white breads and fruits, as well as lower intakes of non-fruit juices or other sugar-sweetened beverages. These findings are in line with the results of ANIBES, a cross-sectional study with a representative sample of 1627 adults and 205 elderlies from Spain, which found that an intake of milk and dairy products (mainly cheeses, whole milk and yogurt/fermented milk), water, fruits and eggs increased across the terciles of breakfast consumers, while that of sugar and sweets decreased across the terciles ${ }^{(12)}$. Food sources found on the highest terciles are known for their beneficial health properties ${ }^{(13)}$.

It was also observed that frequent breakfast consumers predominantly chose milk, known to be a major source of calcium and vitamin D, as well as whole-wheat breads, a good source of fibre, iron and complex of vitamin B. These findings suggest that regular breakfast consumption could serve as a marker of optimal nutrition profiles for adults and elderlies. Furthermore, evidence showed an association between regular breakfast consumption and regulation of appetite due to the consumption of fibre ${ }^{(11)}$. For instance, individuals consuming breakfast more regularly are less likely to skip in-between meals and may choose later dietary intakes more carefully and consciously, with their preference aimed towards healthier food choices. Nevertheless, occasional and breakfast skippers were observed to have a poorer $\operatorname{diet}^{(13)}$, which implies a public health concern. 
Table 2 Energy and nutrient intake at breakfast and total daily intake according to BQI categories for adults and older adults from ISA-Nutrition (2015)

\begin{tabular}{|c|c|c|c|c|c|c|c|c|c|c|c|c|c|c|c|c|c|}
\hline \multirow[b]{4}{*}{ Breakfast dietary intake } & & & & & \multicolumn{12}{|c|}{ Categories of BQI } & \multirow[b]{3}{*}{$P^{\star}$} \\
\hline & \multicolumn{4}{|c|}{ Total population ( $(1143)$} & \multicolumn{4}{|c|}{ Low: 0-3 (n 183) } & \multicolumn{4}{|c|}{ Medium: 4-6 ( $n$ 772) } & \multicolumn{4}{|c|}{ High: 7-10 ( $n$ 188) } & \\
\hline & \multicolumn{2}{|c|}{ Mean (SD) } & \multicolumn{2}{|c|}{ Median (IQR) } & \multicolumn{2}{|c|}{ Mean (SD) } & \multicolumn{2}{|c|}{ Median (IQR) } & \multicolumn{2}{|c|}{ Mean (SD) } & \multicolumn{2}{|c|}{ Median (IQR) } & \multicolumn{2}{|c|}{ Mean (SD) } & \multicolumn{2}{|c|}{ Median (IQR) } & \\
\hline & & & & & & & & & & & & & & & & & \\
\hline Total breakfast energy $(\mathrm{kcal} / \mathrm{d})$ & $364 \cdot 0$ & $142 \cdot 8$ & 347.6 & $279 \cdot 7,431 \cdot 0$ & $313 \cdot 2$ & $179 \cdot 0$ & $282 \cdot 9^{a}$ & $145 \cdot 4,438.5$ & $370 \cdot 1$ & $135 \cdot 8$ & $351.5^{b}$ & $290 \cdot 0,422 \cdot 7$ & $390 \cdot 1$ & 115.9 & $369.9^{c}$ & $308 \cdot 1,446 \cdot 4$ & $<0.001$ \\
\hline $\begin{array}{l}\text { Total grams of foods and } \\
\text { beverages ( } \mathrm{g} / \text { day) }\end{array}$ & 343.2 & 107.2 & 332 & $282 \cdot 7,382 \cdot 9$ & 320.5 & $149 \cdot 1$ & $300 \cdot 9^{a}$ & $244 \cdot 6,366 \cdot 9$ & $336 \cdot 6$ & 93.7 & $325 \cdot 1^{b}$ & $282 \cdot 7,377 \cdot 0$ & 393.0 & 93.4 & $373 \cdot 3^{\mathrm{c}}$ & $334 \cdot 5,440 \cdot 2$ & $<0.001$ \\
\hline Total energy density $(\mathrm{kcal} / \mathrm{g})$ & 1.07 & 0.31 & 1.1 & $0.9,1.3$ & 1.00 & 0.47 & 0.94 & $0.6,1 \cdot 3$ & 1.11 & 0.29 & 1.08 & $0.9,1 \cdot 3$ & 0.99 & 0.19 & 1 & $0.9,1 \cdot 1$ & 0.841 \\
\hline Protein (\%kcal) & $12 \cdot 6$ & $3 \cdot 1$ & 12.4 & $10 \cdot 5,14 \cdot 4$ & 11.3 & 3.7 & $11 \cdot 1^{a}$ & $9 \cdot 3,12 \cdot 9$ & $12 \cdot 6$ & 2.8 & $12 \cdot 3^{b}$ & $10 \cdot 6,14 \cdot 3$ & 13.9 & 2.7 & $13.8^{c}$ & $12 \cdot 3,15 \cdot 5$ & $<0.001$ \\
\hline Carbohydrate (\%kcal) & $52 \cdot 4$ & 9.3 & 52.9 & $47 \cdot 2,57 \cdot 9$ & 53.4 & 13.9 & $55 \cdot 4^{\mathrm{a}}$ & $48 \cdot 2,62 \cdot 0$ & $52 \cdot 1$ & 8.4 & $52 \cdot 3^{\mathrm{b}}$ & $47 \cdot 0,57 \cdot 1$ & 52.8 & 6.7 & $53 \cdot 1^{\mathrm{b}}$ & $48 \cdot 0,57 \cdot 6$ & 0.046 \\
\hline Total fat (\%kcal) & 33.4 & 9.0 & 33.7 & $27.7,39.4$ & 30.9 & 10.6 & 30.4 & $24.1,38.5$ & 34.3 & 8.9 & 34.4 & $29 \cdot 2,40 \cdot 6$ & 32.2 & 7.2 & 32.6 & $27 \cdot 2,37 \cdot 1$ & 0.337 \\
\hline Total SFA (\%kcal) & $12 \cdot 0$ & 4.2 & $12 \cdot 1$ & $9 \cdot 3,14 \cdot 4$ & $10 \cdot 3$ & $5 \cdot 3$ & $9.9^{\mathrm{a}}$ & $6 \cdot 1,13.7$ & $12 \cdot 3$ & 4.0 & $12 \cdot 2^{\mathrm{b}}$ & $9.9,14.6$ & 12.5 & 2.9 & $12.7^{b}$ & $10.7,14.4$ & $<0.001$ \\
\hline Added sugar (\%kcal) & 13.5 & 8.2 & 11.9 & $7 \cdot 6,17 \cdot 1$ & 21.5 & $11 \cdot 0$ & $19 \cdot 2^{a}$ & $12 \cdot 6,27 \cdot 5$ & 12.6 & 6.7 & $11.7^{\mathrm{b}}$ & $8 \cdot 2,16 \cdot 9$ & 9.3 & 4.5 & $8 \cdot 4^{c}$ & $6 \cdot 1,12 \cdot 0$ & $<0.001$ \\
\hline Total fibre ( $/ 100 \mathrm{kcal})$ & 0.56 & 0.23 & 0.52 & $0.43,0.63$ & 0.44 & 0.17 & $0.45^{\mathrm{a}}$ & $0.34,0.53$ & 0.54 & 0.22 & 0.51 & $0.43,0.53$ & 0.74 & 0.25 & $0.71^{\mathrm{c}}$ & $0.55,0.88$ & $<0.001$ \\
\hline Sodium (mg/100 kcal) & $126 \cdot 8$ & 29.9 & 129.8 & $108 \cdot 8,145 \cdot 3$ & $128 \cdot 1$ & 32.9 & $132 \cdot 8^{\mathrm{a}}$ & $107 \cdot 8,147 \cdot 2$ & $128 \cdot 8$ & 29.1 & $131 \cdot 8^{a}$ & $112 \cdot 0,146 \cdot 2$ & $117 \cdot 7$ & 28.5 & $118 \cdot 8^{\mathrm{b}}$ & $99 \cdot 8,133 \cdot 6$ & 0.002 \\
\hline Calcium (mg/100 kcal) & 57.0 & 26.3 & 53.1 & $37.4,74.6$ & 39.8 & 22.1 & $37^{\mathrm{a}}$ & $23 \cdot 1,45 \cdot 4$ & 57.6 & $26 \cdot 2$ & $54^{\mathrm{b}}$ & $38.5,73.8$ & $72 \cdot 1$ & 20.4 & $71 \cdot 2^{\mathrm{c}}$ & $55 \cdot 0,87 \cdot 4$ & $<0.001$ \\
\hline \multicolumn{18}{|l|}{ Total dietary intake } \\
\hline Total energy $(\mathrm{kcal} / \mathrm{d})$ & 1843 & 633 & 1736 & 1396,2164 & 1842 & 607 & 1751 & 1395,2233 & 1859 & 663 & 1751 & 1385,2183 & 1778 & 526 & 1680 & 1444,2025 & 0.374 \\
\hline $\begin{array}{l}\text { Total grams of foods and } \\
\text { beverages ( } \mathrm{g} / \mathrm{day} \text { ) }\end{array}$ & 2731 & 803 & 2632 & 2174,3160 & 2779 & 768 & 2719 & 2247,3164 & 2721 & 808 & 2657 & 2162,3167 & 2724 & 821 & 2530 & 2177,3138 & 0.223 \\
\hline Total energy density $(\mathrm{kcal} / \mathrm{g})$ & 0.69 & 0.19 & 0.67 & $0.56,0$ & 0.68 & 0.19 & 0.67 & $0.55,0.80$ & 0.70 & 0.19 & 0.69 & $0.56,0.83$ & 0.68 & 0.18 & 0.7 & $0.55,0.78$ & 0.673 \\
\hline Protein & $17 \cdot 4$ & 3.7 & $17 \cdot 2$ & $14.9,19.5$ & 17.0 & 3.9 & 16.8 & $14 \cdot 4,19 \cdot 3$ & 17.4 & 3.7 & $17 \cdot 3$ & $14.9,19.5$ & 17.7 & 3.5 & 17.5 & $15 \cdot 3,19 \cdot 8$ & 0.056 \\
\hline Carbohydrate (\%kcal) & 47.9 & 6.7 & $48 \cdot 3$ & $44.0,52 \cdot 3$ & 48.9 & 7.6 & $48 \cdot 8^{\mathrm{a}}$ & $44 \cdot 6,54 \cdot 2$ & 47.8 & 6.7 & $48 \cdot 4$ & $44 \cdot 0,52 \cdot 1$ & $47 \cdot 3$ & 5.6 & $47 \cdot 2^{b}$ & $43.0,51 \cdot 6$ & 0.024 \\
\hline Total fat (\%kcal) & 32.4 & $5 \cdot 3$ & 32.4 & $29 \cdot 2,35 \cdot 9$ & 31.6 & 5.9 & 31.2 & $28 \cdot 3,34.9$ & 32.6 & $5 \cdot 2$ & 32.5 & $29.5,35.8$ & 32.8 & $5 \cdot 2$ & 32.4 & $29.5,36.6$ & 0.158 \\
\hline SFA (\%kcal) & $10 \cdot 6$ & 2.4 & 10.5 & $9 \cdot 0,12 \cdot 2$ & $10 \cdot 2$ & 2.9 & $10 \cdot 2^{\mathrm{a}}$ & $8 \cdot 3,11.9$ & 10.6 & 2.4 & $10.5^{\mathrm{b}}$ & $9 \cdot 1,12 \cdot 2$ & 10.9 & 2.3 & $10 \cdot 6^{\mathrm{b}}$ & $9 \cdot 3,12 \cdot 3$ & 0.038 \\
\hline gar (\%kcal) & $10 \cdot 4$ & 5.6 & 9.8 & $6 \cdot 2,13 \cdot 8$ & 12.6 & 6.5 & $11.9^{\mathrm{a}}$ & $8 \cdot 1,15 \cdot 3$ & 10.3 & 5.5 & $9 \cdot 6^{\mathrm{b}}$ & $6 \cdot 1,13 \cdot 7$ & 8.6 & 4.5 & $8 \cdot 2^{\mathrm{c}}$ & $4.7,11.5$ & $<0.001$ \\
\hline Total fibre $(\mathrm{g} / 1000 \mathrm{kcal})$ & 9.7 & 2.8 & 9.5 & $7 \cdot 7,11 \cdot 3$ & 9.4 & 3.0 & $9 \cdot 1^{a}$ & $7 \cdot 5,11 \cdot 2$ & 9.4 & $2 \cdot 6$ & $9.4^{\mathrm{a}}$ & $7 \cdot 6,11 \cdot 1$ & 11 & 3.0 & $10.5^{\mathrm{b}}$ & $8 \cdot 7,12 \cdot 8$ & $<0.001$ \\
\hline Sodium (mg/1000 kcal) & 1651 & 335 & 1662 & 1431,1889 & 1725 & 313 & $1735^{a}$ & 1520,1966 & 1650 & 339 & $1657^{\mathrm{a}}$ & 1431,1893 & 1579 & 327 & $1596^{b}$ & 1348,1775 & $<0.001$ \\
\hline Calcium (mg/1000 kcal) & $335 \cdot 2$ & 125.5 & $321 \cdot 3$ & $237 \cdot 6,409 \cdot 4$ & 278.2 & 119.4 & $241 \cdot 2^{\mathrm{a}}$ & $191 \cdot 0,346 \cdot 6$ & 334.2 & $122 \cdot 8$ & $318^{\mathrm{b}}$ & $243.0,400 \cdot 0$ & 396.9 & 114.0 & $384^{c}$ & $316 \cdot 3,472 \cdot 1$ & $<0.001$ \\
\hline BHEI-R & 65.5 & 7.8 & 66.3 & $60.7,70.9$ & $\begin{array}{r}61.8 \\
\end{array}$ & 7.9 & $63 \cdot 2^{\mathrm{a}}$ & $57.6,67.3$ & 65.5 & 7.4 & $66 \cdot 1^{\mathrm{b}}$ & $60.9,70.6$ & 69.6 & 7.5 & $70.6^{c}$ & $65 \cdot 8,74 \cdot 3$ & $<0.001$ \\
\hline
\end{tabular}

BQI, Brazilian Breakfast Quality Index; BHEI-R, Brazilian Healthy Eating Index-Revised.

"Differences across BQI categories ( $P$-value) were evaluated using Theil-Sen test. Post hoc Dunn's test was applied for comparing medians across categories of BQI. Medians in the same row with different superscript letters ${ }^{(a-c)}$ are significantly different $(P<0.01)$. 
Table 3 Association of $\mathrm{BQI}$ according to the presence of cardiometabolic risk factors in ISA-Nutrition (2015) assessed using a logistic regression model

\begin{tabular}{lcccc}
\hline & \multicolumn{4}{c}{$\begin{array}{c}\text { Adjusted model for } \\
\text { BQI score* }\end{array}$} \\
\cline { 2 - 4 } Cardiometabolic variables & $n \dagger$ & OR & $95 \% \mathrm{Cl}$ & $P$ \\
\hline Waist circumference & 534 & 0.906 & $0.77,1.06$ & 0.249 \\
BP & 535 & 0.812 & $0.70,0.94$ & 0.005 \\
Fasting glucose & 539 & 0.848 & $0.73,0.98$ & 0.025 \\
HOMA-IR & 536 & 0.856 & $0.74,0.98$ & 0.031 \\
Total cholesterol & 529 & 0.865 & $0.76,0.99$ & 0.035 \\
TG & 529 & 0.974 & $0.83,1.14$ & 0.752 \\
HDL-C & 528 & 0.884 & $0.77,1.02$ & 0.093 \\
LDL-C & 528 & 0.848 & $0.74,0.97$ & 0.016 \\
MetS & 541 & 0.820 & $0.72,0.93$ & 0.003 \\
Overweight & 543 & 0.873 & $0.76,0.99$ & 0.042 \\
\hline
\end{tabular}

BQI, Breakfast Quality Index; HDL-C, high-density lipoprotein cholesterol; LDL-C low-density lipoprotein cholesterol; HOMA-IR, homeostatic model assessment of insulin resistance; MetS, metabolic syndrome.

${ }^{\star}$ Models adjusted for age (years), gender (male or female), BMI $\left(\mathrm{kg} / \mathrm{m}^{2}\right)$, family income per capita ( $\leq 1$ or $>1$ minimum wage), education of the household ( $\leq 9$ or $>9$ years), smoking status (non-smoker or smoker), leisure-time physical activity (meet or do not meet WHO recommendation), self-declared race (White, Asian or mixed race, Native) and Brazilian Health Eating Index-Revised (continuous). †Sample size for each regression model. Only participants with data for all covariates used in the models were included in the analysis.

The nutrient contribution of breakfast relies on the quality and types of foods consumed ${ }^{(9)}$. Evidence suggests that a high-quality breakfast is associated with a decrease in cardiovascular and T2D risk factors ${ }^{(61,62)}$, in agreement with the present study. All associations were adjusted for potential confounders. Given that no causal conclusion can be drawn, these results show a favourable effect on BQI. This might be related to the combination of different food sources at breakfast, as a consequence of maintaining a healthy weight status ${ }^{(62)}$. Although meal skipping is thought to facilitate weight loss ${ }^{(63)}$, dietary guidelines ${ }^{(17,48)}$ recommend consuming a nutrient-dense breakfast because of its health effects. For example, an intake of milk and dairy products has shown beneficial effects on cardiovascular health ${ }^{(64,65)}$. Biological mechanisms may partly explain these effects, in that a combination of calcium, fat and bile acids in the gastrointestinal system is known to inhibit fat re-absorption and improve the ratio of HDL-C:LDL-C $\mathrm{C}^{(66)}$. An intake of dairy foods may decrease calcium level in the cells, regulating the plasma calcium and, as a consequence, inhibiting fatty acid syntheses and stimulating lipolysis. It is suggested that fatty acids found in dairy foods can have a positive effect on LDL-C density ${ }^{(67)}$. Milk proteins such as wheyprotein and casein might have beneficial effects on $\mathrm{BP}^{(68)}$.

Fibres play an important role in helping to control blood glucose levels, improving insulin sensitivity and reducing atherogenic risk factors. Moreover, the benefits of consuming fruit and vegetables may result in a synergic action between nutrients, phytochemicals and food structure ${ }^{(69)}$. It reinforces the importance to distinguish promoting breakfast $v$. promoting a healthy breakfast. Diets that include nutrient-dense foods have been shown to lead to weight loss and reduce disease risk.
A study based on the National Health and Nutrition Examination Survey 2011-14 data of individuals $>2$ years of age ${ }^{(70)}$ used a linear programme model to identify breakfast quality, favouring fruit, cereals and dairy and suggesting less meat, added sugars and fats, but more whole fruits and $100 \%$ juices, more whole grains and more milk and yogurt. This and our results can build on existing dietary patterns to construct dietary guidelines and identify individual meals and/or snacks that need improvement.

\section{Strengths and limitations}

A major strength of the present study is the application of a breakfast index on the population of São Paulo that was previously developed for Brazilians ${ }^{(21)}$. The impact of breakfast quality was distinguished from the overall diet quality, adjusting the models for BHEI- $\mathrm{R}^{(41)}$, considering the role of breakfast in reducing cardiometabolic risk factors. Moreover, it filled the gap in examining BQI and cardiometabolic risk factors in a representative sample of adults and older adults living in a Brazilian urban city. Finally, the present study used statistical techniques to adjust for potential confounding.

However, the present study was not without limitations. Although data on overall breakfast quality and cardiometabolic risk factors are limited, our findings are in accordance with the results of randomised crossover trials. Jacubowicz et al. (2017) reported that breakfast is highly relevant for preserving the active mechanisms involved in glucose and lipid regulation ${ }^{(71)}$. Another study with the duration of 2 weeks found that healthy and lean pre-menopausal women who skipped breakfast showed higher fasting plasma TC and LDL-C than those eating breakfast regularly ${ }^{(72)}$. Other studies also reported lower BMI, fasting glu$\operatorname{cose}^{(29,73,74)}$ and better cardiometabolic risk profiles ${ }^{(29,73,75)}$ in individuals consuming a healthy breakfast.

Some methodological features of the present study should be considered. Differences between drug users and non-drug users were not explored because of the low number of drug users ( $n$ 220). Therefore, we performed analyses after adjusting the regression models for drug use and then considering only non-drug users. Results remained similar between dichotomising drugs and non-drug users and adjusting for significant cardiometabolic outcomes for drug users. Furthermore, breakfast consumption was assessed based on self-reported $24 \mathrm{hR}$, which does not reflect variations in daily food consumption. Standardised methods were used to reduce recall bias, as well as intrapersonal variability was adjusted to decrease these limitations ${ }^{(32,38)}$.

\section{Conclusion}

Healthier breakfast quality is associated with lower odds of cardiometabolic risk factors in adults and older adults in 
São Paulo, Brazil. Findings of the present study suggest that the Brazilian BQI may be a useful method to characterise and develop programmes to promote healthy behaviours, considering the benefits of a good-quality breakfast, and this could be a simple and important public health message.

\section{Acknowledgements}

Acknowledgements: We would like to thank Prof. Dr Chester Luiz Galvão Cesar, Prof. Dr Moisés Goldbaum, Maria Cecilia Goi Porto Alves, all ISA-Capital staff and the researchers of the Dietary Assessment Group (GAC Grupo de Pesquisa de Avaliação do Consumo Alimentar). Financial support: The 2015 Health Survey of São Paulo was supported by the São Paulo Municipal Health Department (grant number 2013-0·235·936-0), São Paulo Research Foundation (grant numbers 2012/22 113-9, 2017/ 05125-7) and the National Council for Scientific and Technological Development (grant number 472 873/ 2012-1). P.V.F. received a master scholarship from the São Paulo Research Foundation (process \#2017/17 348-0) and Coordenação de Aperfeiçoamento de Pessoal de Nível Superior - Brasil (process \#1 745 592). All funders had no role in the design, analysis or writing of this article. Conflict of interest: None. Authorship: P.V.F. was involved with statistical analysis, interpretation of data and writing of the manuscript. J.L.P. and M.A.C. contributed with statistical analysis, interpretation of data and manuscript drafting. A.L.C. was involved in writing and providing critical review of the manuscript. R.M.F. conceived and initiated the 2015 Health Survey of São Paulo, supervised data management and statistical analysis and provided comments and suggestions on all drafts. All authors have read and approved the submitted version. Ethics of buman subject participation: The 2015 ISA-Capital (CAAE no 32344 014.3.0000·5421) as well as the present study (CAAE no 96304 418.9.0000.5421) was approved by the Institutional Review Board of the School of Public Health, University of São Paulo. The present study was conducted according to the guidelines laid down in the Declaration of Helsinki, and all procedures involving research study participants were approved by the Institutional Review Board of the School of Public Health, University of São Paulo. Written informed consent was obtained from all subjects. Verbal consent was witnessed and formally recorded.

\section{Supplementary material}

For supplementary material accompanying this article visit https://doi.org/10.1017/S1368980020002748

\section{References}

1. World Health Organization (2017) Cardiovascular diseases. https://www.who.int/news-room/fact-sheets/detail/cardio vascular-diseases-(cvds) (accessed February 2020).

2. WHO CVD Risk Chart Working Group (2019) World Health Organization cardiovascular disease risk charts: revised models to estimate risk in 21 global regions. Lancet Glob Health $\mathbf{7}$, e1332-e1345.

3. Alvarez-Alvarez I, Toledo E, Lecea O et al. (2019) Adherence to a priori dietary indexes and baseline prevalence of cardiovascular risk factors in the PREDIMED-Plus randomised trial. Eur J Nutr doi: 10.1007/s00394-019-01982-x.

4. Schwingshackl L, Bogensberger B \& Hoffmann G (2018) Diet quality as assessed by the healthy eating index, alternate healthy eating index, dietary approaches to stop hypertension score, and health outcomes: an updated systematic review and meta-analysis of cohort studies. J Acad Nutr Diet 118, 74-100 e111.

5. Simao A, Precoma D, de Andrade J et al. (2014) I cardiovascular prevention guideline of the Brazilian society of cardiology: executive summary. Arq Bras Cardiol 102, 420-431.

6. O'Neil CE, Byrd-Bredbenner C, Hayes D et al. (2014) The role of breakfast in health: definition and criteria for a quality breakfast. J Acad Nutr Diet 114 (Suppl 12), S8-S26.

7. Affenito SG (2007) Breakfast: a missed opportunity. JAm Diet Assoc 107, 565-569.

8. Timlin M \& Pereira M (2007) Breakfast frequency and quality in the etiology of adult obesity and chronic diseases. Nutr Rev 65, 268-281.

9. O'Neil CE, Nicklas TA \& Fulgoni VL (2014) Nutrient intake, diet quality, and weight/adiposity parameters in breakfast patterns compared with no breakfast in adults: national health and nutrition examination survey 2001-2008. J Acad Nutr Diet 114, S27-S43.

10. Gaal S, Kerr MA, Ward M et al. (2018) Breakfast consumption in the UK: patterns, nutrient intake and diet quality: a study from the international breakfast research initiative group. Nutrients. Published online: 30 July 2018. doi: 10.3390/nu10 080999.

11. Gwin J \& Leidy H (2018) A review of the evidence surrounding the effects of breakfast consumption on mechanisms of weight management. Adv Nutr 9, 717-725.

12. Ruiz E, Avila J, Valero T et al. (2018) Breakfast consumption in Spain: patterns, nutrient intake and quality: findings from the ANIBES study, a study from the international breakfast research initiative. Nutrients. Published online: 18 September 2018. doi: 10.3390/nu10091324.

13. Uzhova I, Mullally D, Penalvo JL et al. (2018) Regularity of breakfast consumption and diet: insights from national adult nutrition survey. Nutrients. Published online: 26 October 2018. doi: $10.3390 /$ nu10111578.

14. Liu Y, Tooze JA, Zhang Y et al. (2019) Breakfast consumption is positively associated with usual nutrient intakes among food pantry clients living in rural communities. $J$ Nutr. Published online: 9 November 2019. doi: 10.1093/jn/nxz258.

15. Dietitians Association of Australia (2018) Breakfast: How to eat like a boss! https://daa.asn.au/smart-eating-for-you/ smart-eating-fast-facts/breakfast-how-to-eat-brekkie-like-aboss (accessed January 2020).

16. American Academy of Nutrition and Dietetics (2014) Healthy eating: eat breakfast. http://www.eatright.org/resource/food/ nutrition/healthy-eating/eat-breakfast (accessed September 2019).

17. Brasil, Secretaria de Atenção à Saúde, Departamento de Atenção Básica (2014) Guia Alimentar Para População Brasileira [Dietary Guidelines for the Brazilian Population], 2nd ed. Brasília: Ministério da Saúde. 
18. British Dietetic Association (2019) Healthy Breakfast. https:// www.bda.uk.com/foodfacts/healthy_breakfast (accessed November 2019).

19. Gerritsen S \& Wall C (2017) How we eat: reviews of the evidence on food and eating behaviours related to diet and body size. https://www.health.govt.nz/system/files/documents/ publications/how-we-eat-may17.pdf (accessed November 2019).

20. Aranceta J, Serra-Majem L, Ribas L et al. (2001) Breakfast consumption in Spanish children and young people. Public Health Nutr 4, 1439-1444.

21. Pereira JL, de Castro MA, Hopkins S et al. (2017) Proposal for a breakfast quality index for Brazilian population: rationale and application in the Brazilian National Dietary Survey. Appetite 111, 12-22.

22. Pinto JA \& Carbajal AA (2003) Nutrición y Salud - El Desayuno Saudable: Servicio de Educación Sanitaria y Promoción de la Salud [Breakfast Healthy: Health Education and Health Promotion Service]. Madrid Spaña: Instituto de Salud Pública.

23. Radcliffe BC, Ogden C, Coyne T et al. (2004) Breakfast consumption patterns of upper primary school students in 14 Queensland schools. Nutr Diet 61, 151-158.

24. Alves HJ \& Boog MC (2007) Food behavior in student residence halls: a setting for health promotion. Rev Saude Publica 41, 197-204.

25. O'Dea JA \& Wagstaff S (2011) Increased breakfast frequency and nutritional quality among schoolchildren after a national breakfast promotion campaign in Australia between 2000 and 2006. Health Educ Res 26, 1086-1096.

26. Hallstrom L, Vereecken CA, Labayen I et al. (2012) Breakfast habits among European adolescents and their association with sociodemographic factors: the HELENA (Healthy Lifestyle in Europe by Nutrition in Adolescence) study. Public Health Nutr 15, 1879-1889.

27. Monteagudo C, Palacin-Arce A, Bibiloni MM et al. (2013) Proposal for a Breakfast Quality Index (BQI) for children and adolescents. Public Health Nutr 16, 639-644.

28. O'Neil CE, Byrd-Bredbenner C, Hayes D et al. (2014) The role of breakfast in health: definition and criteria for a quality breakfast. J Acad Nutr Diet 114, S8-S26.

29. Iqbal K, Schwingshackl L, Gottschald M et al. (2017) Breakfast quality and cardiometabolic risk profiles in an upper middle-aged German population. Eur J Clin Nutr 71, 1312-1320.

30. Delley M \& Brunner TA (2019) Breakfast eating patterns and drivers of a healthy breakfast composition. Appetite 137, 90-98.

31. Gibney MJ, Barr SI, Bellisle F et al. (2018) Breakfast in human nutrition: the international breakfast research initiative. Nutrients. Published online: 1 May 2018. doi: 10.3390/nu10 050559.

32. Fisberg RM, Sales CH, Fontanelli MM et al. (2015) Health survey of Sao Paulo with focus in nutrition: rationale, design, and procedures. Nutrients. Published online: 1 February 2018. doi: 10.3390/nu10020169.

33. Matsudo S, Araújo T, Matsudo V et al. (2001) Questionário internacional de atividade física (IPAQ) estudo de validade e reprodutibilidade no Brasil [International Physical Activity Questionnaire (IPAQ): study of validity and reliability in Brazil]. RBAFS 6, 5-18.

34. World Health Organization (2010) Global Recommendations on Physical Activity for Health. Geneva: World Health Organization.

35. World Health Organization (2000) Consultation on obesity: preventing and managing the global epidemic: WHO Technical Report Series no. 894. Geneva: WHO.

36. Lebrão ML \& Duarte YAO (2003) SABE: Saúde, Bem-estar e Envelhecimento: O Projeto Sabe No Município de São Paulo: Uma Abordagem Inicial [Health, Well-Being and Aging: The
SABE Study in São Paulo], 1st ed. Brasília, Brazil: Organização Pan-Americana de Saúde.

37. Carvalho AM, Piovezan LG, Selem SSC et al. (2014) Validation and calibration of self-reported weight and height from individuals in the city of São Paulo. Rev Bras Epidemiol 17. doi: $10.1590 / 1809-4503201400030013$.

38. Moshfegh AJ, Rhodes DG, Baer DJ et al. (2008) The US department of agriculture automated multiple-pass method reduces bias in the collection of energy intakes. Am J Clin Nutr 88, 324-332.

39. Núcleo de Estudos e Pesquisas em Alimentação (2011) Tabela Brasileira de Composição de Alimentos: TACO [Brazilian Food Composition Table: TACO], 4th ed. Campinas: NEPA-UNICAMP.

40. Tabela Brasileira de Composição de Alimentos (2017) Tabela Brasileira de Composição de Alimentos: Food Research Center (Version 6.0) [Brazilian Food Composition Database: Food Research Center (Version 6.0)]. São Paulo: Universidade de São Paulo.

41. Previdelli AN, Andrade SC, Pires M et al. (2011) A revised version of the Healthy Eating Index for the Brazilian population. Rev Saude Publica 45, 794-798.

42. Brasil, Secretaria de Atenção à Saúde, Coordenação-Geral da Política de Alimentação e Nutrição (2006) Guia Alimentar Para População Brasileira: Promovendo a Alimentação Saudável [Dietary Guidelines for the Brazilian Population: Promoting Healthy Eating], 1st ed. Brasília: Ministério da Saúde.

43. World Health Organization (2003) Diet, nutrition and the prevention of chronic diseases. Joint WHO/FAO Technical Report Series [Diet, nutrition and the prevention of chronic diseases. Joint WHO/FAO Technical Report Series] no. 916. Geneva, Switzerland: WHO.

44. Institute of Medicine (2005) Dietary Reference Intakes for Water, Potassium, Sodium, Chloride, and Sulfate. Washington, DC: The National Academies Press.

45. Guenther PM, Reedy J \& Krebs-Smith SM (2008) Development of the healthy eating index-2005. J Am Diet Assoc 108, 1896-1901.

46. Sposito AC, Caramelli B, Fonseca FA et al. (2007) IV Diretriz brasileira sobre dislipidemias e prevenção da aterosclerose: departamento de aterosclerose da sociedade brasileira de cardiologia [Brazilian guideline for dyslipidemia and atherosclerosis prevention: department of atherosclerosis of Brazilian society of cardiology]. Arq Bras Cardiol 88 (Suppl. 1), 2-19.

47. Block G, Hartman AM, Dresser CM et al. (1986) A data-based approach to diet questionnaire design and testing. $\mathrm{Am} \mathrm{J}$ Epidemiol 124, 453-469.

48. Dietary Guidelines Advisory Committee (2015) Scientific Report of the 2015 Dietary Guidelines Advisory Committee: Advisory Report to the Secretary of Health and Human Services and the Secretary of Agriculture. Washington: DC: U.S. Department of Agriculture, Agricultural Research Service.

49. World Health Organization (1995) Physical status: the use and interpretation of anthropometry. WHO Technical Report Series, 854. Geneva: WHO.

50. Alberti KG, Eckel RH, Grundy SM et al. (2009) Harmonizing the metabolic syndrome: a Joint Interim Statement of the International Diabetes Federation Task Force on Epidemiology and Prevention; National Heart, Lung, and Blood Institute; American Heart Association; World Heart Federation; International Atherosclerosis Society; and International Association for the Study of Obesity. Circulation 120, 1640-1645.

51. Sociedade Brasileira de Diabetes (2014) Diretrizes da Sociedade Brasileira de Diabetes 2013-2014 [Guidelines of Brazilian Diabetes Society 2013-2014]. São Paulo: AC Farmacêutica. 
52. Xavier HT, Izar MC, Neto JR et al. (2013) V Brazilian guidelines on dyslipidemias and prevention of atherosclerosis. Arq Bras Cardiol 101, 1-20.

53. Malachias MVB, Gomes MAM, Nobre F et al. (2016) VII Diretriz brasileira de hipertensão arterial: diagnóstico e classificação [Brazilian guideline of arterial hypertension: diagnosis and classification]. Arq Bras Cardiol 107 (Suppl. 3), 7-13.

54. Geloneze B, Vasques ACJ, Stabe CFC et al. (2009) HOMA1-IR and HOMA2-IR indexes in identifying insulin resistance and metabolic syndrome: Brazilian Metabolic Syndrome Study (BRAMS). Arq Bras Endocrinol Metabol 53, 281-287.

55. German Institute of Human Nutrition Potsdam-Rehbrü cke DIfE, Department of Epidemiology (2012) The Multiple Source Method (Version 1.0.1). https://nugo.dife.de/msm (accessed July 2019).

56. Perry EA, Thomas H, Samra HR et al. (2017) Identifying attributes of food literacy: a scoping review. Public Health Nutr 20, 2406-2415.

57. Reedy J, Krebs-Smith SM, Miller PE et al. (2014) Higher diet quality is associated with decreased risk of all-cause, cardiovascular disease, and cancer mortality among older adults. J Nutr 144, 881-889.

58. Rong S, Snetselaar LG, Xu G et al. (2019) Association of skipping breakfast with cardiovascular and all-cause mortality. J Am College Cardiol 73, 2025-2032.

59. Bellisle F, Hebel P, Salmon-Legagneur A et al. (2018) Breakfast consumption in French children, adolescents, and adults: a nationally representative cross-sectional survey examined in the context of the international breakfast research initiative. Nutrients. Published online: 9 August 2018. doi: 10.3390/nu10081056.

60. Ruiz E, Avila J, Valero T et al. (2018) Breakfast consumption in Spain: patterns, nutrient intake and quality: findings from the ANIBES study, a study from the international breakfast research initiative. Nutrients. Published online: 18 September 2018. doi: 10.3390/nu10091324.

61. Toh DWK, Koh ES \& Kim JE (2019) Lowering breakfast glycemic index and glycemic load attenuates postprandial glycemic response: A systematically searched meta-analysis of randomized controlled trials. Nutrition 71, 110634. doi: 10.1016/j.nut.2019.110634.

62. O'Neil CE \& Nicklas TA (2019) Breakfast consumption versus breakfast skipping: the effect on nutrient intake, weight, and cognition. Nestle Nutr Inst Workshop Ser 91, 153-167.

63. Nagata JM, Garber AK, Tabler JL et al. (2018) Prevalence and correlates of disordered eating behaviors among young adults with overweight or obesity. J Gen Intern Med 33, 1337-1343.
64. Givens DI (2017) Saturated fats, dairy foods and health: a curious paradox? Nutr Bull 42, 247-282.

65. Lee M, Lee H \& Kim J (2018) Dairy food consumption is associated with a lower risk of the metabolic syndrome and its components: a systematic review and meta-analysis. BrJ Nutr 120, 373-384.

66. Boon N, Hul GBJ, Stegen JHCH et al. (2007) An intervention study of the effects of calcium intake on faecal fat excretion, energy metabolism and adipose tissue mRNA expression of lipid-metabolism related proteins. Int $J$ Obes 31, $1704-1712$

67. Sjogren P, Rosell M, Skoglund-Andersson C et al. (2004) Milk-derived fatty acids are associated with a more favorable LDL particle size distribution in healthy men. J Nutr 134, 1729-1735.

68. Park YW \& Nam MS (2015) Bioactive peptides in milk and dairy products: a review. Korean J Food Sci Anim Resour 35, 831-840.

69. Fardet A (2010) New hypotheses for the health-protective mechanisms of whole-grain cereals: what is beyond fibre? Nutr Res Rev 23, 65-134.

70. Vieux F, Maillot M, Rehm CR et al. (2019) Designing optimal breakfast for the United States using linear programming and the NHANES 2011-2014 database: a study from the international breakfast research initiative (IBRI). Nutrients 11, 1374

71. Jakubowicz D, Wainstein J, Landau Z et al. (2017) Influences of breakfast on clock gene expression and postprandial glycemia in healthy individuals and individuals with diabetes: a randomized clinical trial. Diabetes Care 40, 1573-1579.

72. Farshchi H, Taylor M \& Macdonald I (2005) Deleterious effects of omitting breakfast on insulin sensitivity and fasting lipid profiles in healthy lean women. Am J Clin Nutr 81, 388-396.

73. di Giuseppe R, Di Castelnuovo A, Melegari C et al. (2012) Typical breakfast food consumption and risk factors for cardiovascular disease in a large sample of Italian adults. Nutr Metab Cardiovasc Dis 22, 347-354.

74. Milla PG, Johns PC \& Aguero SD (2014) Asociación del consumo de desayuno y la calidad de vida en adultos mayores autonomos chilenos [Association between breakfast intake and quality of life among self-sufficient chilean elderly]. Nutr Hosp 30, 845-850.

75. Cahill LE, Chiuve SE, Mekary RA et al. (2013) Prospective study of breakfast eating and incident coronary heart disease in a cohort of male US health professionals. Circulation 128, $337-343$. 